\title{
Saccade Target Selection in Frontal Eye Field of Macaque. I. Visual and Premovement Activation
}

\author{
Jeffrey D. Schall, Doug P. Hanes, Kirk G. Thompson, and Dana J. King \\ Department of Psychology, Wilson Hall, Vanderbilt University, Nashville, Tennessee 37240
}

\begin{abstract}
We investigated how the brain selects the targets for eye movements, a process in which the outcome of visual processing is converted into guided action. Macaque monkeys were trained to make a saccade to fixate a salient target presented either alone or with multiple distractors during visual search. Neural activity was recorded in the frontal eye field, a cortical area at the interface of visual processing and eye movement production. Neurons discharging after stimulus presentation and before saccade initiation were analyzed. The initial visual response of frontal eye field neurons was modulated by the presence of multiple stimuli and by whether a saccade was going to be produced, but the initial visual response did not discriminate the target of the search array from the distractors. In the latent period before saccade initiation, the activity of most visually responsive cells evolved to signal the location of the target. Target selection occurred through suppression of distractor evoked activity contingent on the location of the target relative to the receptive field. The evolution of a signal specifying the location of the salient target could be dissociated from saccade initiation in some cells and could occur even when fixation was maintained. Neural activity in the frontal eye fields may participate in or be the product of the decision process guiding eye movements.
\end{abstract}

[Key words: frontal eye field, saccade, visual search, target selection, eye movement, visual system, oculomotor system, sensorimotor transformation, decision]

Rapid eye movements called saccades direct gaze to conspicuous features in the scene (Yarbus, 1967; Viviani, 1990). How the brain selects the target for each eye movement is unknown. The necessary visual computations begin in the geniculostriate visual system through the selective visual responses of neurons (Hubel and Wiesel, 1968). Visual signals proceed through multiple areas in prestriate cortex representing different functional specializations (Colby and Duhamel, 1991; Felleman and Van

\footnotetext{
Received Mar. 14, 1995; revised June 7, 1995; accepted June 21, 1995.

We thank Amy Ihrig, Chris Porter, and Frank Tu for assistance with data acquisition and analysis; Narcisse Bichot, Kyle Cave, Michael Goldberg, and the reviewers for many helpful comments on the manuseript; the animal care staff of the Vanderbilt Vision Research Center, Bill Gentry for machine work; Phil Vermulen and Lonnie Shimp for electronic work; and Barbara Hendricks for preparing the manuscript. This work was supported by R01-EY08890, a fellowship from the Alfred P. Sloan Foundation, a grant and a fellowship from the McDonnell-Pew Program in Cognitive Neuroscience, P30-EY08126 and T32-EY07135 to the Vanderbilt Vision Research Center, P30-HD15052 to the John F. Kennedy Center for Research on Education and Human Development, and F32-EY06495 to K.T.

Correspondence should be addressed to Dr. Jeffrey D. Schall, Department of Psychology, Wilson Hall, Vanderbilt University, Nashville, TN 37240.

Copyright (C) 1995 Society for Neuroscience $0270-6474 / 95 / 156905-14 \$ 05.00 / 0$
}

Essen, 1991; Merigan and Maunsell, 1993). Selecting the target for an eye movement entails combining or comparing signals from the different cortical areas. One structure mediating visuomotor transformations is the frontal eye fields (FEF), in the rostral bank of the arcuate sulcus. Anatomical studies show that FEF projects efferents to oculomotor structures including the caudate nucleus, the deep layers of the superior colliculus and brainstem pre-oculomotor nuclei (Fries, 1984; Schnyder et al., 1985; Huerta et al., 1986; Segraves and Goldberg, 1987; Stanton et al., 1988a,b; Shook et al., 1990, 1991; Parthasarathy et al., 1992; Segraves, 1992), and FEF receives afferents from most prestriate visual cortical areas (Schall et al., 1995). Physiological studies show that FEF neurons discharge in relation to saccadic. eye movements and have visual responses (Bruce and Goldberg, 1985; Schall, 1991a).

In all previous investigations of FEF, monkeys have been presented with a single stimulus as the target for the saccade (Mohler et al., 1973; Wurtz and Mohler, 1976; Suzuki and Azuma, 1977, 1983; Pigarev et al., 1979; Kubota et al., 1980; Goldberg and Bushnell, 1981; Bruce and Goldberg, 1985; Schall, 1991a). To investigate the process of target selection explicitly, the presence of a stimulus must be dissociated from whether that stimulus is the target for the eye movement. This dissociation can be achieved using a visual search task in which a target stimulus is presented with multiple distractor stimuli (Treisman, 1988; Wolfe and Cave, 1990). We investigated saccade target selection by training thesus monkeys to perform a target detection task supplemented by a pop-out visual search task.

Preliminary reports of some of these data have appeared (Schall and Hanes, 1993; Thompson et al., 1993).

\section{Materials and Methods}

Subjects and surgery. Data were collected from two Macaca mulatta weighing 4-10 kg. The animals were cared for in accordance with the National Institute of Health's Guide for the Care and Use of Laboratory Animals and the guidelines of the Vanderbilt Animal Care Committee. The surgical procedures have been described (Schall, 1991b; Hanes et al., 1995).

Tasks. Using operant conditioning with positive reinforcement, the monkeys were trained to perform a series of tasks in which reward was contingent on either executing or withholding a saccade to a target presented alone or with distractors. The different task conditions were used to determine cell type, map the spatial extent of the response field, determine the effects of saccade planning and execution on cell responses as well as identifying the effects of presenting the target with distractors. Each trial began when the monkey fixated a central white spot (CIE chromaticity coordinates $x=0.278, y=0.249$ ). Following a specified interval of fixation the target was presented either alone or with distractors. Within each block the target was presented at one of eight positions varying in direction and/or eccentricity to map the response field. An isoluminant color change of the central fixation spot from white to either green (CIE $x=0.179, y=0.696$ ) or red (CIE $x$ 
$=0.626, \mathrm{y}=0.338$ ) signaled the monkey to either execute ( $g o$ ) or withhold (nogo) a saccade, respectively. We refer to this color change as the trigger signal. The fraction of nogo trials in a set of blocks was $0 \%$ (all go trials), $100 \%$ (all nogo trials) or $12 \%$. The time of the trigger signal could be varied relative to target presentation. In the basic condition the trigger signal coincided with target presentation (Fig. 1A); this condition usually used $0 \%$ nogo trials. In the instructed delay condition, the monkey was required to maintain fixation on the central spot after the target was presented for a variable length of time ranging from 50 to 1000 msec. The color change of the central spot signaled the monkey to make or withhold a saccade to the target (Fig. 1B); the instructed delay condition usually included $12 \%$ nogo trials to discourage premature movements. Instructed delay trials provided a means of dissociating visual from motor responses. In the no-saccade condition on every trial the red nogo trigger signal preceded target presentation by a fixed interval (300-500 msec) (Fig. 1C). This condition was used to assess the activation of neurons in response to stimuli presented when the monkey was instructed that no saccade should be made. The first and third conditions were repeated presenting the target with distractors (Fig. $1 D, E$ ). The target was presented at one of eight positions around the central fixation spot and distractors appeared at the other seven positions with the same eccentricity. The monkey was required to make a saccade to the stimulus that was different. For this investigation targets and distractors were distinguished by either color (red vs green) or form (high vs low spatial frequency squarewave, high contrast checkerboards). Within a set of trials the target and distractors remained the same (e.g., always red among green), but as often as possible we collected data with the target and distractor stimuli switched (e.g., green among red). In some sets of blocks a fraction of catch trials were included in which only distractors were presented and the monkey was rewarded for maintaining fixation. If the monkey failed to direct its gaze properly at any time, the trial was aborted and no reinforcement was given. We will refer to the condition when the target is presented alone as detection trials and when the target is presented with distractors as visual search trials.

Stimuli were presented on a video monitor (Conrac 7241, $60 \mathrm{~Hz}$ interlaced) using computer controlled raster graphics (PDP 11/83, Peritek VCH-Q, $512 \times 512$ resolution). The fixation spot subtended $0.22^{\circ}$ of visual angle. The stimuli were presented on a $10 \mathrm{~cd} / \mathrm{m}^{2}$ white background and were adjusted to be isoluminant as measured with a Minolta CA-100 spectrophotometer. To provide approximately equal visibility, the size of stimuli was scaled from $0.3^{\circ}$ of visual angle at $4^{\circ}$ eccentricity to $1^{\circ}$ of visual angle at $10^{\circ}$ eccentricity, in proportion to cortical magnification (Hubel and Wiesel, 1974; Dow et al., 1981; Tootell et al., 1982; Van Essen et al., 1984).

Data collection and analysis. Standard techniques were used to col lect these data (Schall, 1991b; Hanes et al., 1995). The experiments were under computer control (PDP 11/83) which presented the stimuli, recorded the eye movements, collected single unit activity, and delivered the juice reward. Eye position was monitored with a scleral search coil sampled at $200 \mathrm{~Hz}$ and stored with event times on disk for off-line analysis. For successful performance monkeys had to fixate to within $0.5-1^{\circ}$ of the fixation spot and to within $1-2^{\circ}$ of the targets. Single units were recorded using glass-coated platinum-iridium or tungsten microelectrodes. The action potentials were amplified, filtered, and discriminated conventionally with a time-amplitude window discriminator and sampled at $1 \mathrm{kHz}$. Single units were admitted to the database if the amplitude of the action potential was sufficiently above background to reliably trigger the window discriminator, the action potential waveshape was invariant, and the isolation could be sustained for a sufficient period for testing.

Saccades were detected using an algorithm that first searched for significantly elevated gaze velocity. Eye velocity was determined by digital differentiation of the position signal; the threshold velocity was $30 \% \mathrm{sec}$. Saccade initiation was then defined as the beginning of the monotonic change in eye position preceding the high velocity gaze shift. Saccade termination was defined as the end of the monotonic change in eye position after the eye velocity fell below the threshold.

Neural activity was inspected using raster displays combined with averaged spike density functions derived from convolving each spike train with a gaussian filter. We selected a standard deviation of $10 \mathrm{msec}$ for this filter to indicate reliably the changes in discharge rate. The initial visual response to stimulus presentation was determined by measuring the discharge rate during the first $50 \mathrm{msec}$ of activation adjusted for the average response latency of each cell. The final presaccadic

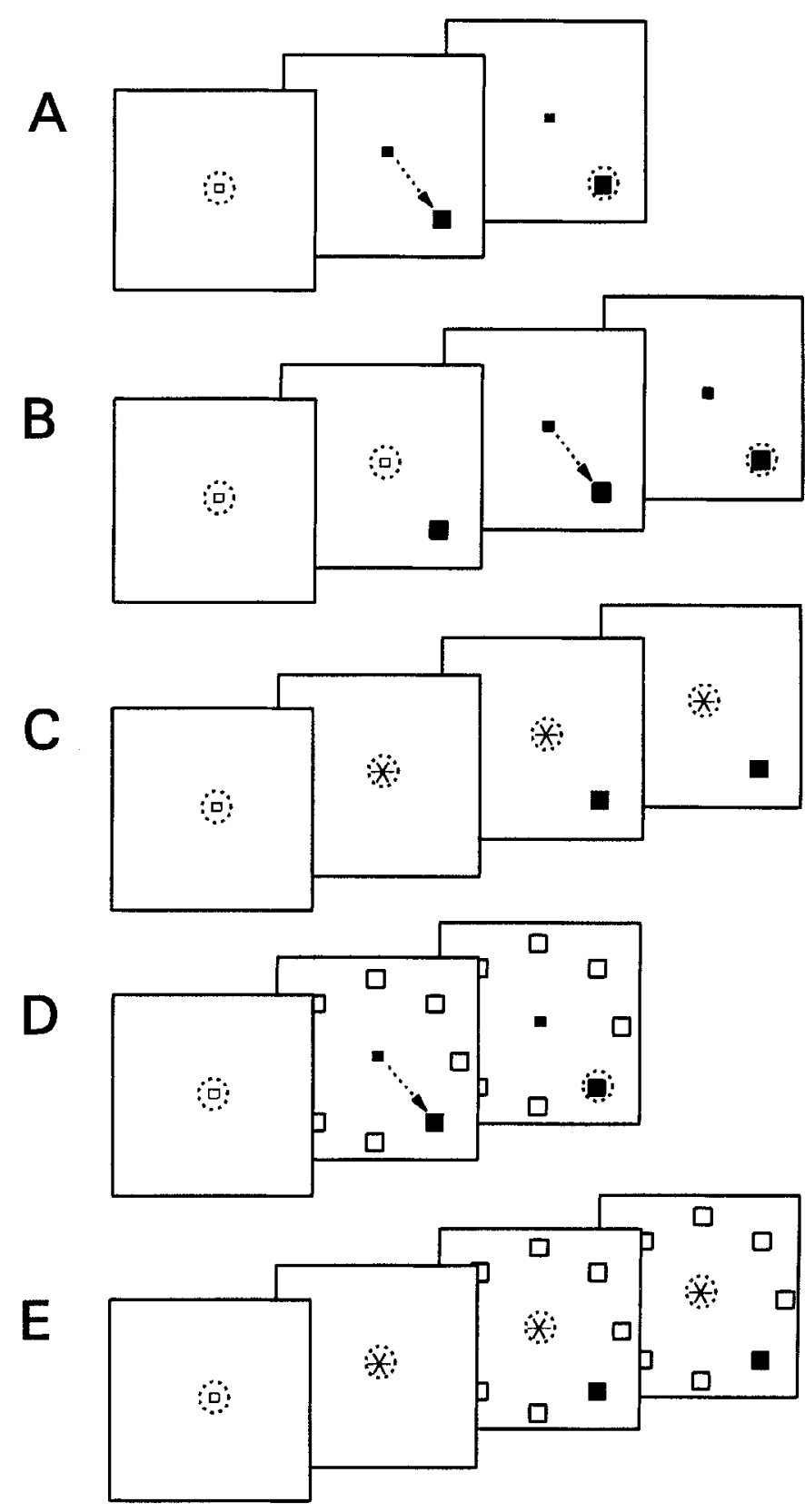

Figure 1. Schematic representation of trial conditions. The dashed circle represents the monkeys current point of fixation, and the arrow represents the saccade to the target. Each trial began with presentation of a white spot on a video monitor (front panels). A change of color of the fixation spot (trigger signal) instructed monkeys either to shift gaze to the target (go trial) or to maintain fixation (nogo trial). For illustration a solid square indicates the go signal, and an asterisk indicates the nogo signal. The color change of the fixation spot could occur before, simultaneous with or after presentation of the stimuli. $A$, Detection trial with the target presented alone with no delay from the go trigger signal. $B$, Instructed delay detection trial with the target presented alone before the go trigger signal. $C$, Nogo detection trial with the target presented after the instruction to maintain fixation. $D$, Visual search trial with the target presented with distractors simultaneously with the go trigger signal. $E$, Nogo search trial with the display presented after the instruction to maintain fixation. 
activation was determined by measuring the discharge rate during the $50 \mathrm{msec}$ immediately preceding the initiation of the saccade. A variety of statistical tests were performed to compare levels of activation in specific intervals across trial conditions or target positions. To determine whether the activity of cells varied significantly with target direction, we used a one-way analysis of variance of the discharge rate in the selected interval of each trial as a function of target direction. In cases with significant variation a modified least significant difference test was then applied to determine the range of positions that were in the response field (Sokal and Rohlf, 1981). To compare the activation measured in specific intervals across experimental conditions, a nonparametric median test, which compares the central tendency of the distributions, was used because the distributions being compared deviated from normality and/or had different counts (Siegal and Castellan, 1988).

To quantify the variation of activity with location when the target was presented alone, the magnitude of response as a function of target direction was fit with a gaussian function of the form

$$
\Lambda(\phi)=B+R \cdot \exp \left(-1 / 2\left[(\phi-\Phi) / T_{\Phi}\right]^{2}\right),
$$

where activation $(A)$ as a function of meridional direction $(\phi)$ depends on the baseline discharge rate $(B)$, maximum discharge rate $(R)$, optimum direction $(\Phi)$, and directional tuning $\left(T_{\phi}\right)$. Bruce and Goldberg (1985) have shown that this function effectively characterizes the spatial pattern of responsiveness of FEF neurons. As described below, we found neurons that exhibited a different pattern of variation of activity as a function of target direction during visual search. To quantitatively characterize whether a pattern of ccntral facilitation and surrounding suppression existed, the variation of neural activation as a function of target direction was described with a difference-of-gaussians (DOG) equation of the form

$$
\begin{aligned}
A(\phi)=B+R_{+} & \cdot \exp \left(-1 / 2\left[\left(\phi-\Phi_{+}\right) / T_{+}\right]^{2}\right) \\
& -R_{-} \cdot \exp \left(-1 / 2\left[\left(\phi_{-}-\mathbf{\Phi}_{-}\right) / T_{-}\right]^{2}\right) .
\end{aligned}
$$

Positive subscripts denote the central facilitatory component, and negative subscripts, the broader antagonistic component. We compared the quality of fit of both functions using the Model Selection Criterion (MSC) statistic:

$$
M S C=\ln \left[\sum_{i=1}^{n}\left(a(\phi)_{i}-\bar{a}\right)^{2} / \sum_{i=1}^{n}\left(a(\phi)_{i}-A(\phi)\right)^{2}\right]-2 \cdot p / n,
$$

where $a(\phi)$ is the presaccadic activity measured for the different target directions, $\bar{a}$ is the average presaccadic firing rate, $A(\phi)$ is the activity expected based on the best fit gaussian or difference of gaussian function, $p$ is the number of free parameters, and $n$ is the number of data points (Akaike, 1976). This statistic, which is derived from Akaike's Information Criterion (Akaike, 1973; Sakamoto et al., 1986), compares the quality of fit provided by two competing models for the same observed data by relating the coefficient of determination to the number of free parameters. The difference-of-gaussian equation by virtue of having more free parameters should be able to account for more of the variance of activity as a function of target direction than the single gaussian function. The MSC statistic quantifies how much more of the total variance must be accounted for by the difference-of-gaussian model using seven parameters as compared to the single gaussian model with four parameters to select which provides a better overall fit. The model yielding a higher MSC statistic was judged to provide the better fit to the data.

\section{Results}

Three hundred-fifteen neurons were recorded in 234 penetrations from two monkeys from the rostral bank of the arcuate sulcus. The location of the penetrations in monkey $Q$ is indicated in Figure 1 of Schall (1991a). The penetrations in monkey B have now been histologically localized to the FEF in the rostral bank of the arcuate sulcus. From this large sample of cells, 64 had visually evoked activity and/or saccade-related activity and provided sufficient data in the necessary trial conditions for this report. As observed previously, many neurons in FEF were activated to different degrees in association with visual stimulus presentation and saccade execution (Bruce and Goldberg, 1985; Schall, 1991a). For this investigation neurons were analyzed that responded in relation to visually guided saccades to stimuli at eccentricities ranging from $4-10^{\circ}$. Visual responses were identified by their consistent latency relative to the time of stimulus appearance. Saccade-related activity was measured if significantly elevated activation occurred in the $50 \mathrm{msec}$ interval immediately before the saccade (determined with a one-way ANOVA). Nearly all of the neurons we analyzed for this report were activated by visual stimuli. One subpopulation of neurons responded exclusively to the presentation of visual stimuli with no saccade-related activation $(n=10$ ) (see Figs. 2, 4, 5). A few neurons exhibited weak or no visual activation followed by a robust discharge immediately preceding and during saccadic eye movements ( $n=7$ ) (see Fig. 7). Other visually responsive cells discharged in a sustained fashion following target presentation until saccade initiation $(n=47)$ (see Figs. $6,8,9)$. Neurons that discharged from target presentation until saccade generation were of particular interest because they were active during the processes of target identification and response selection. Distinguishing between visually evoked and saccade related activation was aided by use of the instructed delay condition which separated presentation of the target from the signal triggering the saccade. Unfortunately, no data were collected using memoryguided saccades to a flashed target which would have allowed us to distinguish visuomovement cells from tonic visual cells (Bruce and Goldberg, 1985). The absence of this test, however, does not invalidate the relevance or interpretability of the results we will report. Neural activity in the interval preceding a saccade may be a persisting response to a visual stimulus or may be responsible for the generation of the eye movement. In either case, the ultimate assignment of a specific functional role to the premovement neural activation and specification of how visual signals are converted into motor commands awaits elucidation of the synaptic organization within FEF and other structures. To adopt the most conservative stance, we will distinguish only between phasic and tonic visual cells in this article. We will report an analysis of the initial visual and final premovement activation of neurons in FEF. We are currently analyzing the timecourse of evolution of selective activity (Thompson et al., 1995).

\section{Activity after stimulus presentation}

A critical question we examined was whether the visual responses of FEF neurons discriminated the target from the distractors in a search array. The activity of a representative phasic visual cell in response to a target presented alone and with distractors is shown in Figure 2. This cell illustrates one of our main findings; the initial visual response elicited by the visual search stimulus array does not distinguish whether the stimulus in the receptive field is the target or a distractor. In the instructed delay condition this neuron responded with a fixed latency following presentation of the target and exhibited no activity related to saccade generation (Fig. 2A). This neuron responded when the target was presented alone in a linited range of positions. The discharge rate measured in the first $50 \mathrm{msec}$ of activation decreased in a graded fashion as the target appeared further from the receptive field (Fig. $2 B$ ). This variation of activity with target direction during the detection condition was statistically significant (one-way ANOVA $F=41.90$, df $=116$, $p<0.001$ ), and was well fit by a gaussian function (Fig. $2 C$ ). In contrast, when presented the search array, the response of the cell elicited by the different stimulus configurations did not vary significantly ( $\Lambda$ NOV $\Lambda F-1.80$, df -87 ). In other words, the activity elicited when the target fell in the receptive field was 


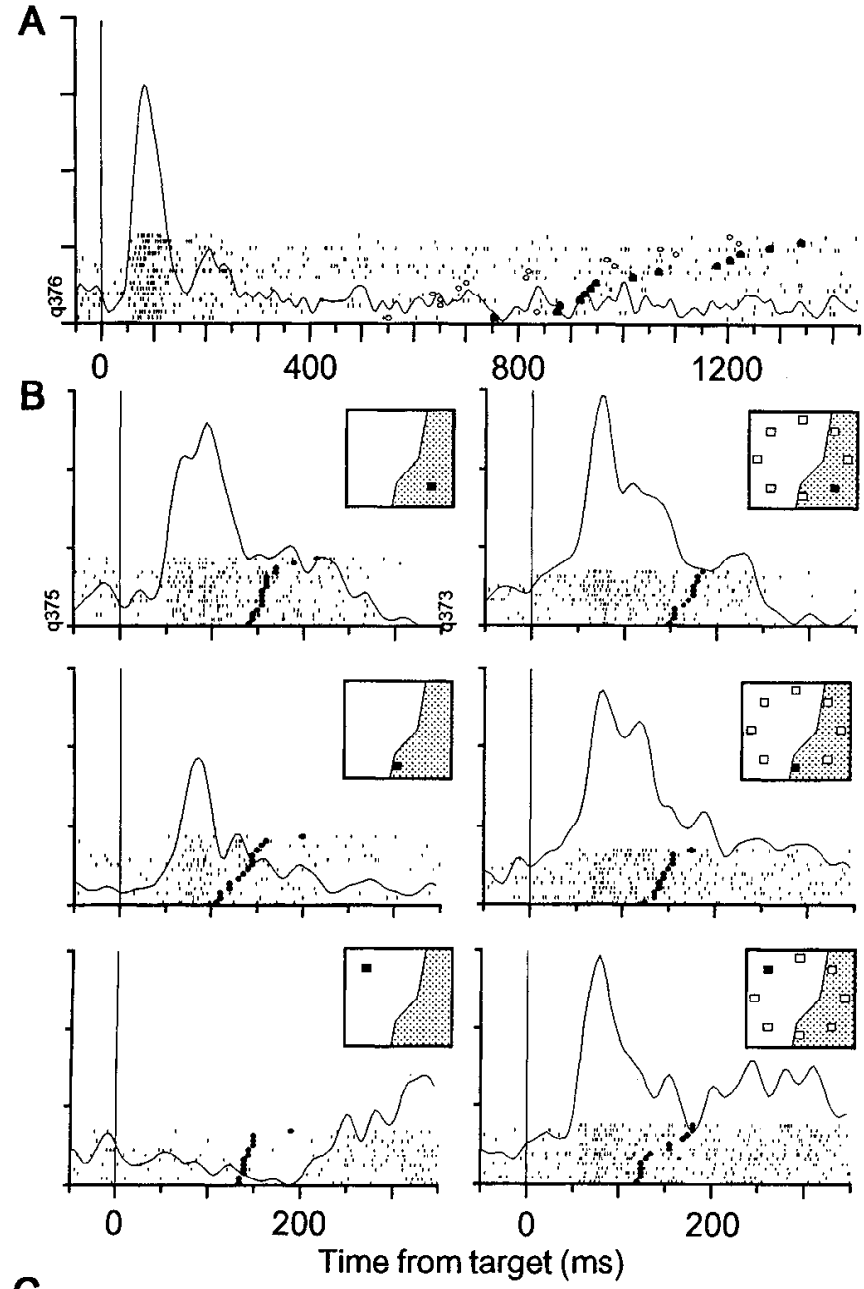

C

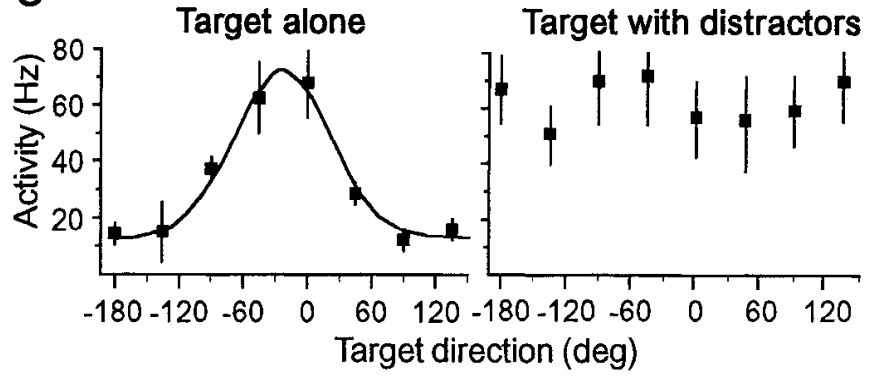

Figure 2. Visual cell activity. A, Activity collected during instructed delay condition. In the raster displays vertical tickmarks represent times of neuronal discharges. The rasters are aligned on target presentation and sorted according to the interval between target presentation and saccade initiation. The time of occurrence of the delayed trigger signal is indicated by the open circle, and the time of saccade initiation is indicated by the solid circle in each raster line. Superimposed on the raster is the average spike density function obtained by convolving each spike train with a gaussian filter; the ordinate scale represents $200 \mathrm{~Hz}$. $B$, Activity of the same neuron in response to a target presented alone or with distractors during visual search. The rasters are all aligned on the time of stimulus presentation; saccade initiation is indicated by the solid circle in each raster line. The inset cartoon indicates the configuration of the stimuli to which the monkey was responding when it made a saccade; the shaded region indicates the extent of the receptive field. The target was a green $1.0^{\circ}$ square presented alone or with $71.0^{\circ}$ red squares at $10^{\circ}$ eccentricity. The response elicited by the target presented alone at three of the eight possible locations is shown on the left. The activity in trials when the target appeared at the same locations but accompanied by distractors at the other locations is shown on the right. The ordinate represents $150 \mathrm{~Hz}$. C, Activity as a function of direction of the target presented alone (left) or with distractors (right).

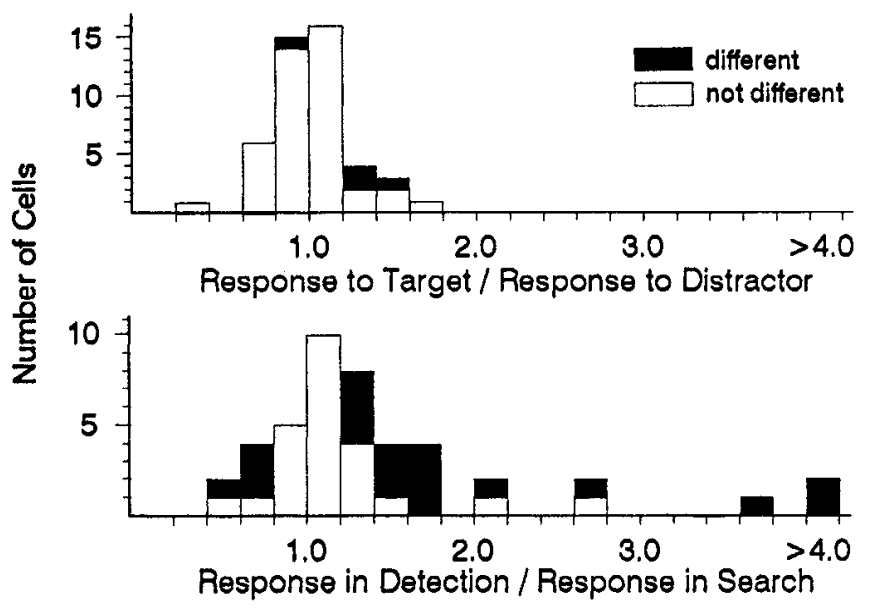

Figure 3. Magnitude of initial visual response to target and distractor stimuli in the receptive field. The top histogram shows the ratios of the mean response for each cell evoked by the search array when the target or a distractor was at the most sensitive position in the receptive field. The bottom histrogram shows the ratios of the mean response for each cell evoked by the target when it was at the most sensitive position in the receptive field during detection and search trials. Solid bins represent statistically significant ratios.

no different from that elicited when distractors fell in the receptive field (Fig. 2B,C).

Every visually reśponsive cell in FEF had a spatially restricted receptive field and responded best to the target when it fell at one of the eight array positions. To determine whether FEF neurons distinguished visual stimuli on the basis of color or form, we compared the initial activation elicited by the search array when the target fell at the most responsive position with the initial activation elicited by the search array when the target was outside the receptive field. Figure 3 (top) shows the ratios of the mean discharge rate during the first $50 \mathrm{msec}$ of activation evoked when the target of the search array was in the receptive field divided by the mean discharge rate during the first $50 \mathrm{msec}$ of activation evoked when distractors were in the receptive field. None of the phasic visual neurons and just four of the tonic visual neurons responded significantly differently to the target versus a distractor in the receptive field. Three of the tonic visual cells responded significantly more when the target fell in the receptive field (least significant ANOVA $F=8.22, \mathrm{df}=81, p$ $<0.001)$, and one responded only slightly but significantly less to the target (ANOVA $F=2.95$, df $=98, p<0.001$ ). The overall lack of selective visual responses was evident when the target was distinguished from distractors by either color or form.

We also compared the initial visual responses of neurons when the targct was presented alone in the response field versus when it was presented in the receptive field with distractors at the other positions (Fig. 3 bottom). For 5 out of 10 phasic visual cells the initial $50 \mathrm{msec}$ of activity evoked by the target presented alone was significantly greater than that evoked by the target presented in the visual search display (least significant

$\leftarrow$

By convention, the $0^{\circ}$ angle is on the right horizontal meridian; positive angles progress counterclockwise, and negative angles, clockwise. Vertical lines indicate 1 SEM where the value is larger than the size of the symbol. The parameters of the best-fit gaussian function of direction of the target presented alone were $B=15 \mathrm{~Hz}, R=62 \mathrm{~Hz}, \Phi=-29^{\circ}$, and $T_{\phi}=40^{\circ}$. 

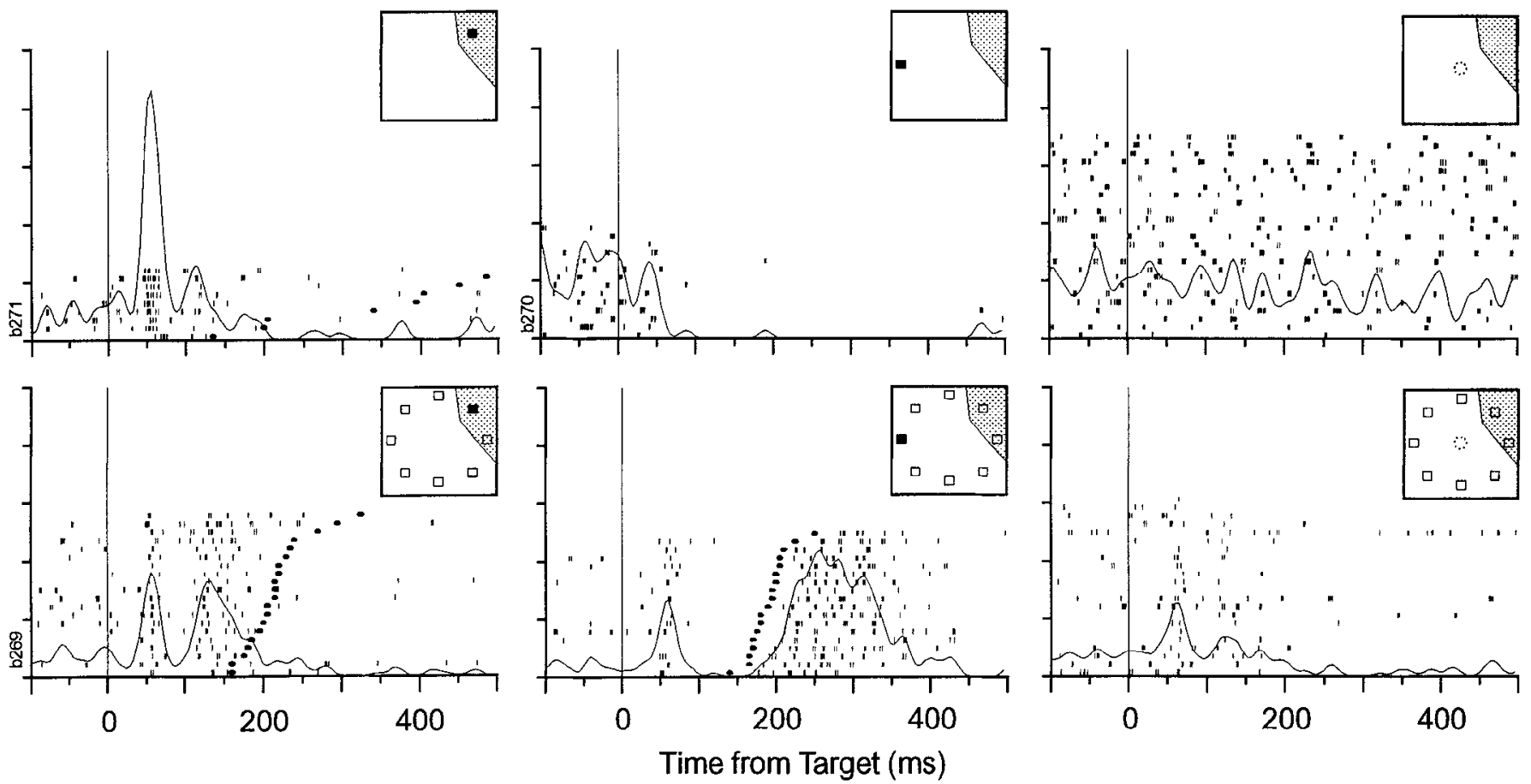

Figure 4. Responses of a visual neuron to the target presented alone, with distractors and in catch trials. Conventions as in Figure 2 except as noted. The target was an achromatic square, 3 cycle/deg checkerboard presented alone or with 7 square, 4.5 cycle/deg distractors. The top panels show the activity collected when the target was presented alone in the receptive field (left), alone outside the receptive field (middle) or not at all in catch trials (right). The bottom panels show the activity collected in search trials with the target in the most sensitive part of the receptive field (left), with distractors in the receptive field and the target in the opposite hemifield (middle) or with only distractors in catch trials (right). The ordinate scale represents $250 \mathrm{~Hz}$

median test with 281 trials, $\chi^{2}=5.32, \mathrm{df}=1, p=0.021$; ; one phasic visual cell responded significantly less in detection as compared to search trials (median test with 337 trials, $\chi^{2}=14.5$, df $=1, p=0.0001$ ). Significantly greater responses during the detection trials as compared to the visual search trials were also observed in 11 of 34 tonic visual cells tested (least significant median test with 410 trials, $\chi^{2}=6.62, \mathrm{df}=1, p=0.010$ ); the opposite was found in 3 cells (least significant median test with 90 trials, $\chi^{2}=5.12$, df $=1, p=0.024$ ). Examining the level of activation in all trials of all cells, we found significantly greater activation by the target presented alone as compared to when it was presented with distractors (median test with 2303 trials, $\chi^{2}=32.9$, df $=1, p<0.001$ ).

Most of the phasic visual cells resembled the one illustrated in Figure 2 in failing to discriminate the target from a distractor at any time during the trial. However, we encountered a few phasic visual neurons with two phases of activity, an early phase that did not discriminate whether the target or distractors were in the receptive field followed by a later phase that was selective for target presence in the receptive field. Figure 4 shows a phasic visual cell that had two distinct phases of visual activation. When the target was presented alone in the response field of the cell, it elicited a brisk, transient response with $50 \mathrm{msec}$ latency. In contrast, when the target was presented in the hemifield opposite the receptive field, the cell became suppressed until the saccade was made, even if the saccade was delayed by instruction. The latency of the suppression was comparable to that of the excitatory response. In catch detection trials in which no target was presented and the monkey was required to maintain fixation of the central spot, the neuron continued to fire at its resting rate. Suppression by a stimulus in the hemifield contra- lateral to a cell's receptive field was observed in other cells (see Figs. 8, 9) but has not been reported before for FEF visual neurons.

During visual search this cell exhibited a very different pattern of activity. Presentation of the search display evoked an early, transient burst of activity at the same latency as that of the response to the target presented alone. The initial burst evoked by the search array was attenuated significantly relative to that observed when the target was presented alone (median test with 177 trials, $\chi^{2}=35.61$, df $=1, p<0.001$ ). The visual response may have been reduced due to the suppressive influence invoked by the presence of stimuli in the ipsilateral visual field. In addition, the magnitude of the initial response did not distinguish whether the target or a distractor fell in the receptive field (ANOVA $F=0.723$, df $=145$ ). However, this neuron exhibited a subsequent reactivation specifically when the stimulus in the receptive field was the target of the search array. When the target was not in the receptive field, suppression ensued after the initial burst until the saccade was made. In search catch trials in which only distractors were presented and the monkey was rewarded for maintaining fixation, the activity after the initial burst decayed more gradually. Evidently, the suppression observed when the target was in the hemifield opposite the receptive field was an active process contingent on preparation of a saccade to the target outside the receptive field.

This FEF cell illustrates another noteworthy finding. When the target of the search array was in the receptive field, the time of occurrence of the selective second phase of activity was synchronized with target presentation and not with saccade initiation. Despite the development of an apparently reliable signal of target location, saccades were initiated at variable intervals rel- 

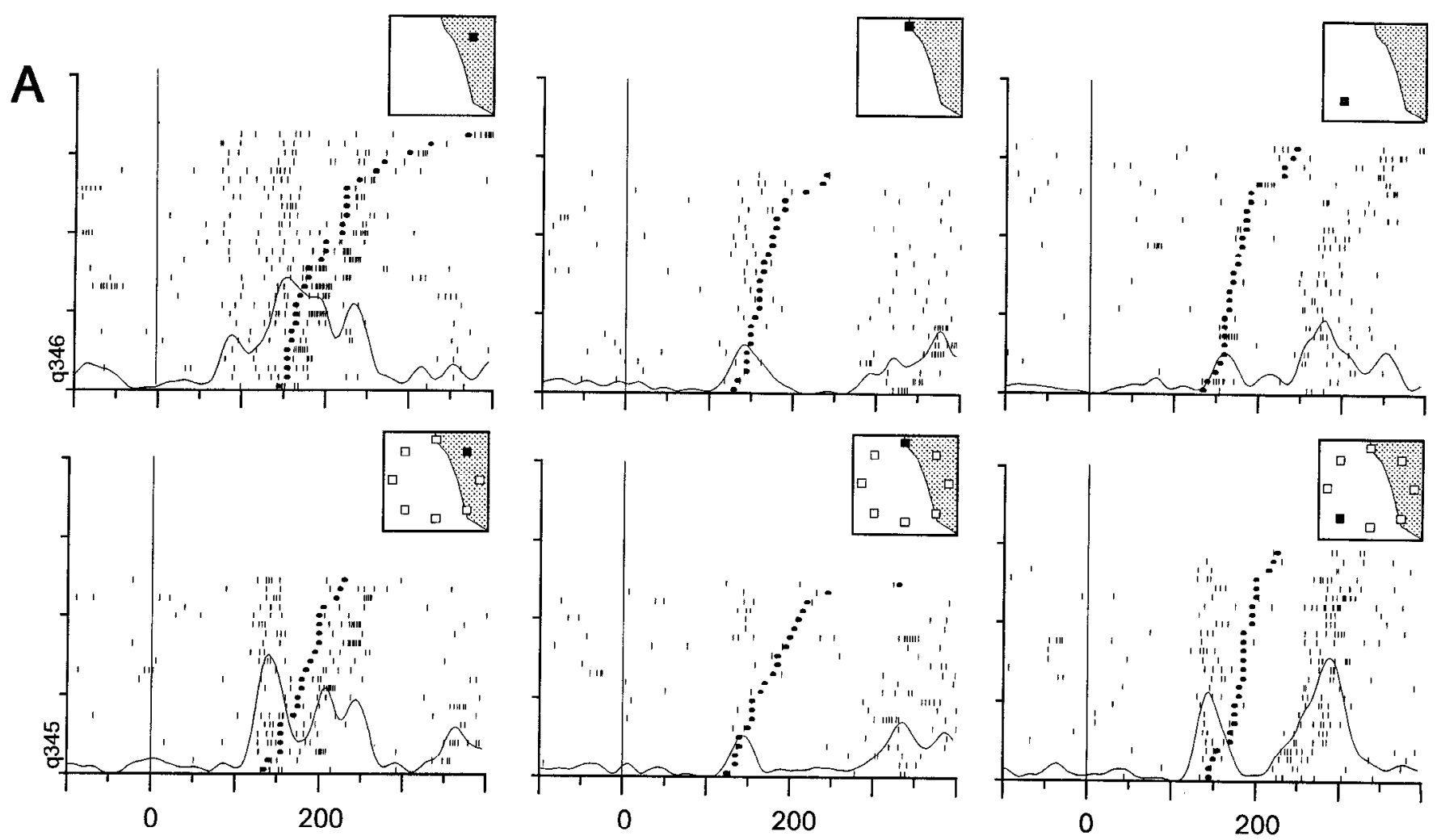

Time From Target (ms)

B

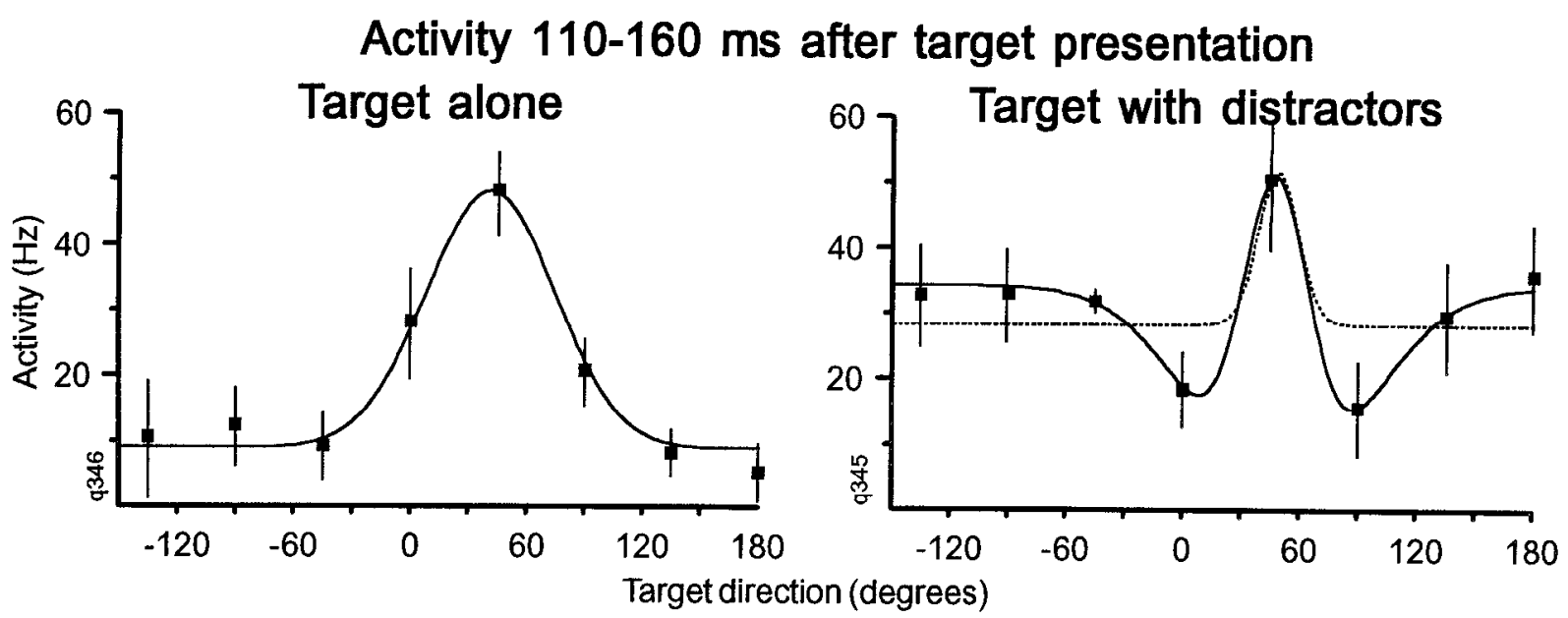

Figure 5. Responses of a visual neuron to the target presented alone or with distractors. Conventions as in Figure 2 except as noted. A. The target was a green square presented alone or with 7 red square distractors at $10^{\circ}$ eccentricity. The ordinate scale represents $200 \mathrm{~Hz}$. $B$, Discharge rate measured from 110 to $160 \mathrm{msec}$ after stimulus presentation plotted as a function of target direction when the target is presented alone and with distractors. Best-fit gaussian and difference-of-gaussian functions are shown. The parameters of the gaussian function best-fit to the activation when the target was presented alone are $B=7 \mathrm{~Hz}, R=46 \mathrm{~Hz}, \Phi=40^{\circ}$, and $T_{\phi}=36^{\circ}$. The parameters of the difference-of-gaussian function best-fit to the activation when the target was presented with distractors are $B=34 \mathrm{~Hz}, R_{+}=49 \mathrm{~Hz}, \Phi_{+}=47^{\circ}$, and $T_{+}=8^{\circ}, R_{-}=30 \mathrm{~Hz}, \Phi_{-}=49^{\circ}$, and $T_{-}=42^{\circ}$.

ative to this reactivation. In particular, the shorter latency saccades (Fig. 4, bottom of lower left raster) occurred just as the second phase of activity had commenced, but the longer latency saccades (top of raster) did not occur until as much as $200 \mathrm{msec}$ after the selective reactivation.

The cell shown in Figure 5 exhibited a similar long latency activation that was specific for target location and also shows another aspect of saccade target selection in FEF. The neuron had an early (70-100 msec) and a late (110-160 msec) phase of activity when the target was presented alone in its response field. The magnitude of both the early and the late phase of activity decreased in a gaussian fashion as the individual target appeared more distant from the receptive field; the magnitude of the later period of activity is plotted in Figure $5 B$. In contrast, when the target was presented with distractors, the carly phase of activity was significantly reduced (median test with 383 trials, 
$\chi^{2}=42.2$, df $\left.=1, p<0.0001\right)$; however, the later phase of visual activity was not different from the activity evoked by the target alone (median test with 83 trials, $\chi^{2}=0.01$, df $=1$ ). Unlike the neuron shown in Figure 4, though, the magnitude of this late phase of activity varied with the location of the target relative to the receptive field (ANOVA $F-5.92$, df $-1.95, p$ $<0.0001)$. The variation of activity with target direction was not gaussian (Fig. 5B). When the search target fell at the most sensitive position within the receptive field, the magnitude of the long latency response was maximal. When the target of the search array fell at locations on the edge of the cell's response field, the level of the delayed activity evoked by the distractors in the response field was less than when the target fell at a more distant locations.

To account for this pattern of variation, a difference of gaussian function was needed to provide an adequate fit of the data. We had two motivations for using the difference of gaussian function. First, the difference-of-gaussian equation has been used to model the facilitatory and suppressive zones of retinal ganglion cells (Rodieck, 1965; Enroth-Cugell and Robson, 1966) and of neurons in the primary visual cortex (Hawken and Parker, 1987). Second, it provided a quantitative means by which to ascertain whether neural activity exhibited the specific pattern of variation with target direction during visual search characterized by a zone of higher activity flanked by zones of lower activity as compared to more distant locations. For this cell the MSC (see Materials and Methods) of 0.161 for the best-fit difference of gaussians was greater than the MSC of 0.073 obtained for the best-fit single gaussian curve; thus, the difference of gaussian provided a better fit of the data than did the single gaussian. In other words, during visual search for a salient target in an array of distractors, suppressive flanks around the receptive field modulated the late phase of visual activation of this neuron. Also, as observed in the cell illustrated in Figure 4, the occurrence of the late period of target specific activation for this neuron was better correlated with the time of target presentation than with the time of saccade initiation.

\section{Activity before the saccade}

Most of the FEF neurons we analyzed discharged following target presentation until saccade initiation. Whereas the discharge rate evoked by presentation of the search array did not discriminate whether the stimulus in the neurons' receptive field was the target or a distractor, the activity of these neurons in the interval immediately before saccade initiation varied according to the location of the target relative to the receptive field. We are currently analyzing these data to estimate the time course of this transition from indiscriminant to selective activation. Our preliminary findings indicate that on average $140 \mathrm{msec}$ after search array presentation, single cell activity begins to discriminate whether the target or a distractor is in the receptive field (Thompson et al., 1995).

Two representative neurons with premovement activity will be illustrated followed by a description of the properties of the premovement phase of activity. The neuron shown in Figure 6 had a relatively long visual response latency of $100 \mathrm{msec}$. The fact that the onset of activation was synchronized on the time of target presentation indicates that the early activity was probably not related exclusively to movement generation. When the target of the search array appeared in the sensitive center of the response field (Fig. 6A, lower left panel), the neuron discharged in the same manner as when the target appeared alone in the response field (Fig. 6A, upper left panel). When the target of the search array appeared at a location distant from the response field (Fig. 6A, lower right), the cell responded to the distractor in the response field at an initial rate comparable to that observed when the target was in the response field. The level of activity then, however, never grew to reach the level it did when the target was in the response field. When the target of the search array appeared at a location adjacent to the response field (Fig. $6 A$, lower center), this cell exhibited a brief period of stimulus evoked activation followed by a sustained period of suppression leading up to the saccade. Thus, during visual search trials the first $50 \mathrm{msec}$ of activation of this neuron did not predict saccade direction because it did not distinguish whether the target or a distractor was in the receptive field (ANOVA $F=0.63$, df $=$ 68). During the latent period before the saccade, the activity of this cell changed according to where the target was located relative to the receptive field. Ultimately, in the $50 \mathrm{msec}$ preceding saccade initiation the discharge rate varied significantly with target direction (ANOVA $F=11.7$, df $=68, p<0.0001$ ) (Fig. $6 B$ ). Notably, the magnitude of presaccadic activation decreased from the center of the response field in a nonmonotonic fashion. The presence of suppression mechanisms beside the response field of this cell was tested by comparing how well a single gaussian and a difference of gaussian function fit the data. The variation of activity in the $50 \mathrm{msec}$ preceding initiation of the saccade to the search target was not as well fit by a single gaussian function (MSC $=0.432$ ) as it was by a difference of gaussians (MSC $=0.501$ ) (Fig. $6 B$ ). This indicates that a specific suppressive mechanism modulated the activation of this neuron before saccade generation.

Other FEF neurons had weak or no visual response and were more active in relation to the saccade. The beginning of activation of this population of cells is correlated with saccade initiation (Segraves and Park, 1993; Hanes et al., 1995). The activity of one such cell before saccades made to a target presented alone or with distractors is shown in Figure 7 . When the target was presented alone, the neuron discharged before saccades in a particular range of directions with a graded reduction in activity as saccade direction deviated from the optimum direction. The variation with direction of the activity measured in the 100 msec before saccade initiation was well described by the gaussian function (Fig. 7B). Before saccades to the target presented with distractors this neuron exhibited generally the same growth and level of activity. We found for this cell that the variation with direction of the activity measured in the $100 \mathrm{msec}$ period before saccade initiation, although well accounted for by a single gaussian function (MSC $=1.16$ ), was accounted for better by a difference-of-gaussian function (MSC $=1.22$ ). Hence, even neurons with very weak visual responses or presaccadic preludes may exhibit the evolution toward specific activity shaped by suppressive flanks. Notably, though, when we repeated the curve-fitting analysis using the activity measured just $50 \mathrm{msec}$ before the saccade, we found that the single gaussian function provided a better fit than did the difference-of-gaussian function.

A central finding of this investigation was that the activity of FEF neurons evolved before saccade initiation to signal whether the stimulus in the response field was the target for the eye movement. The oneway ANOVA demonstrated significant variation in the level of activity in the $50 \mathrm{msec}$ immediately preceding the saccade to the search target in $96 \%$ of the sample of neurons. For all cells discharging until saccade initiation we compared the magnitude of presaccadic activation when the tar- 

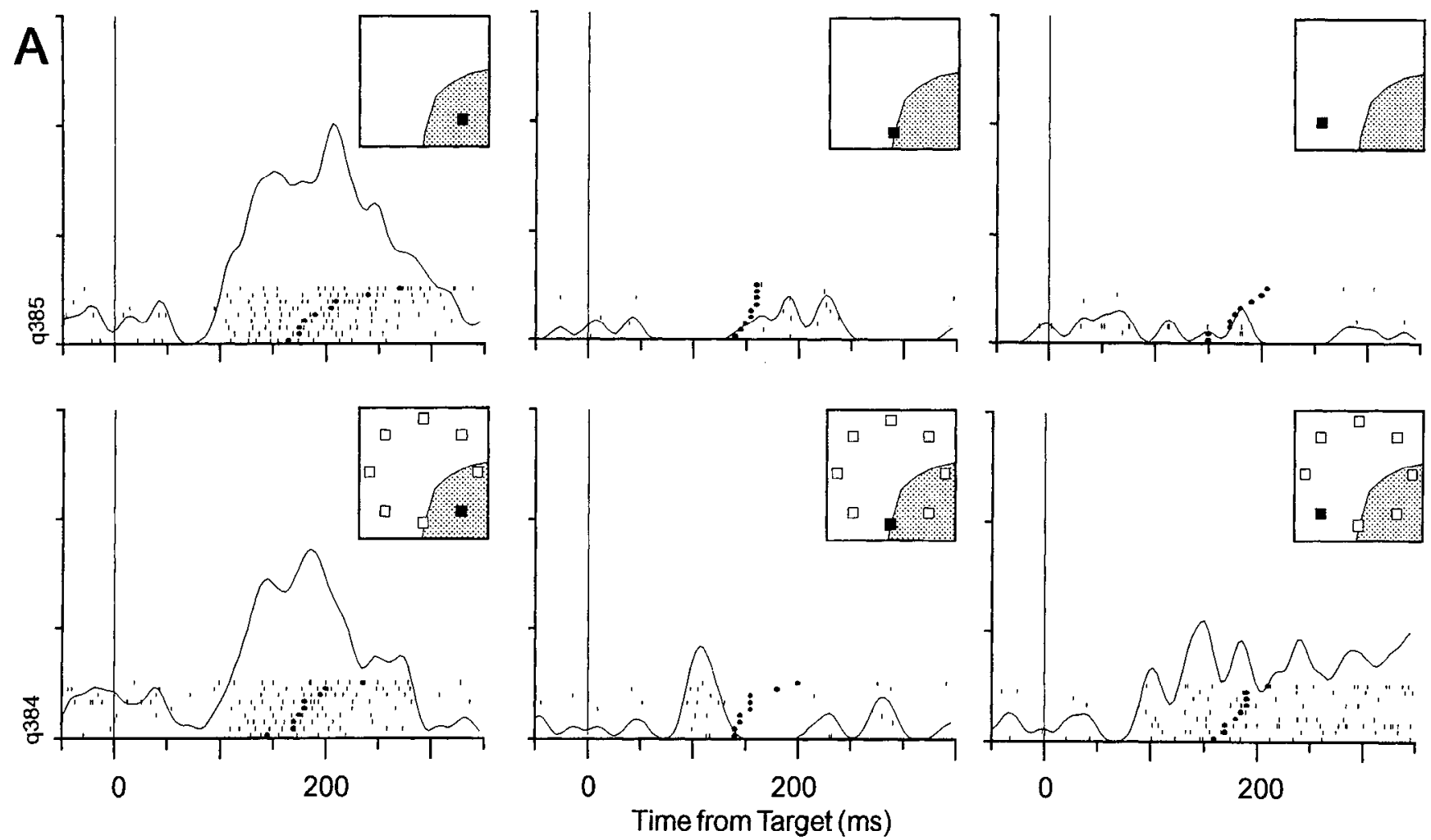

B

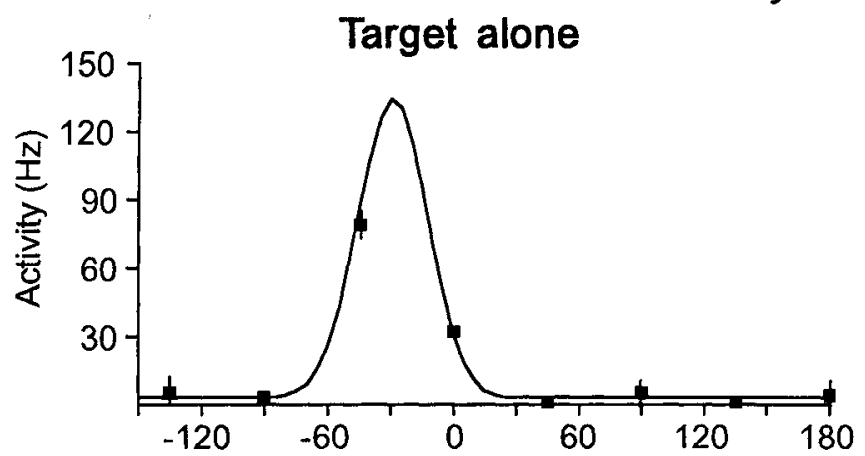

Activity $50 \mathrm{~ms}$ before saccade
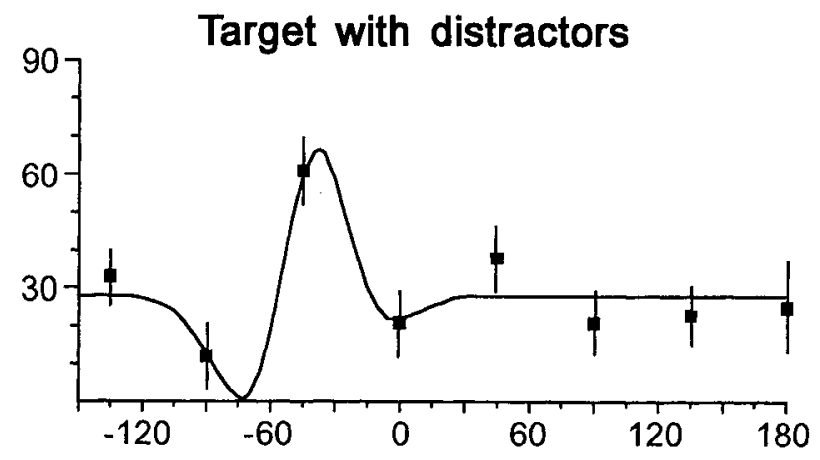

Target direction (degrees)

Figure 6. Activity of FEF cell with visual and premovement activity during detection and search trials. Conventions as in Figure 2 except as noted. $A$, The target was a green square presented alone or with 7 red squares at $10^{\circ}$ eccentricity. The ordinate represents $150 \mathrm{~Hz}$. $B$, Discharge rate measured in the $50 \mathrm{msec}$ interval before saccade initiation as a function of target direction for detection and search trials. The parameters of the gaussian function best fit to the activity preceding the saccade to the target alone were $B=3 \mathrm{~Hz}, R=111 \mathrm{~Hz}, \Phi=-29^{\circ}$, and $T_{\phi}=18^{\circ}$. The parameters for the difference-of-gaussian curve best fit to the activity preceding the saccade to the target presented with distractors were $B=28$ $\mathrm{Hz}, R_{+}=120 \mathrm{~Hz}, \Phi_{+}=-41^{\circ}, T_{+}=17^{\circ}, R_{-}=85 \mathrm{~Hz}, \Phi_{-}=-47^{\circ}$, and $T_{-}=24^{\circ}$.

get was presented alone in the movement field with the magnitude when the target was presented with distractors. When tested individually, only $15 \%$ of the cells with strong visual responses coupled with premovement activity were significantly more active before saccades to targets presented alone (least significant median test with 59 trials, $\chi^{2}=4.08, \mathrm{df}=1, p=0.0435$ ), and just $8 \%$ were more active before saccades to the target presented in the search display (least significant median test with 48 trials, $\chi^{2}=5.34$, df $=1, p=0.0208$ ). The remaining $77 \%$ of the tonic visual cells and all of the cells with predominantly premovement activity had equivalent discharge rates before saccades made to the target presented alone or with distractors. Analysis of the premovement activation in all trials for these cells indicated no significant difference in discharge rate before saccades to the target presented alone or with distractors (median test with 2011 trials, $\chi^{2}=2.80, \mathrm{df}=1$ ). We have also found that the saccaderelated burst of FEF cells has the same time course before saccades made to a target presented alonc or during visual search (Hanes et al., 1995).

\section{FEF response field organization}

To determine the incidence of neurons in which suppressive mechanisms may be involved in saccade guidance, we analyzed the pattern of variation of presaccadic activity as a function of target location during visual search by comparing the quality of fits obtained with single gaussian and difference of gaussian 

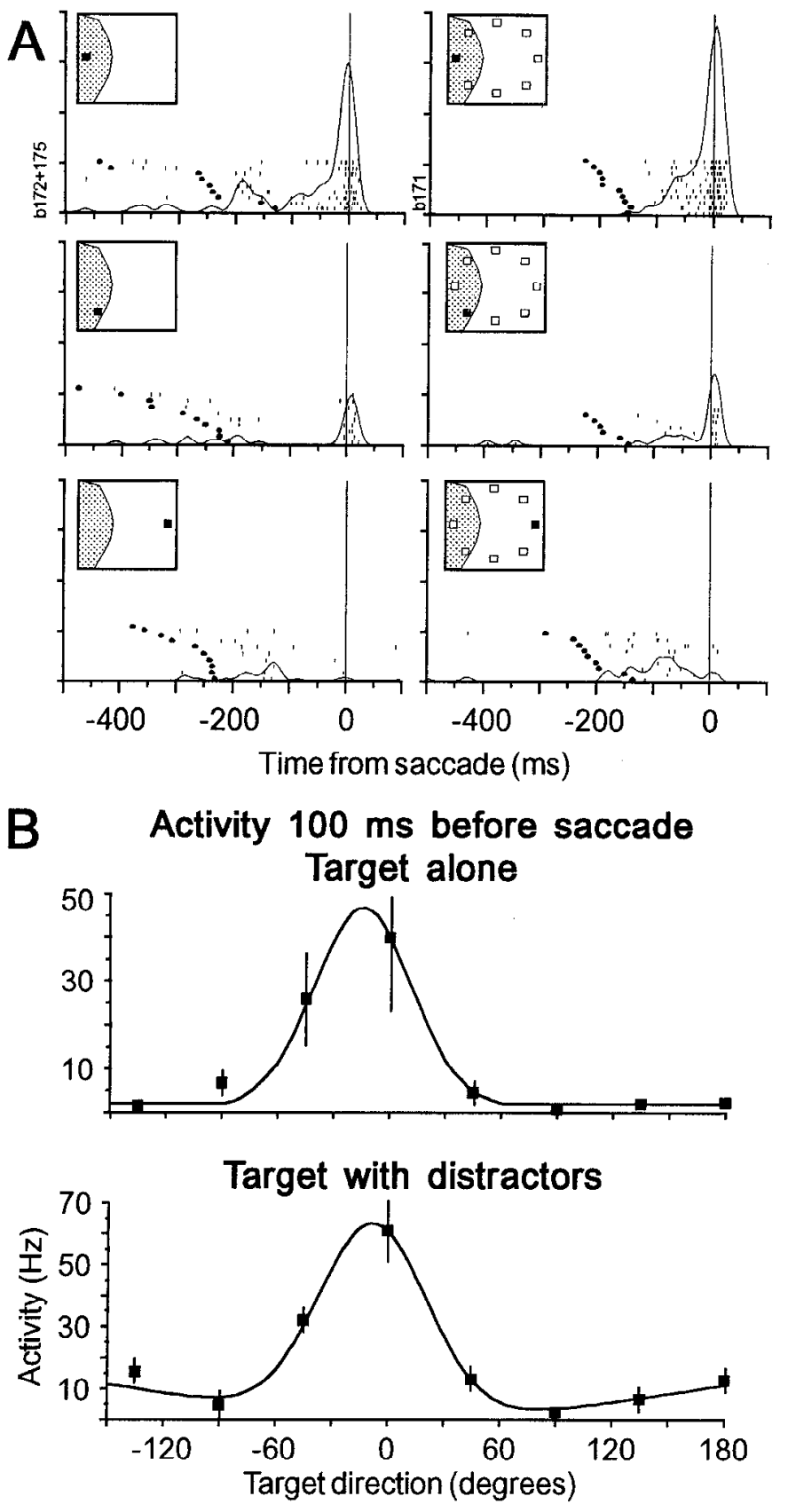

Figure 7. FEF cell with weak visual and strong movement-related activity. $A$, The target was an achromatic $1.0^{\circ}$ square, 3 cycle/deg checkerboard presented alone or with $71.0^{\circ}$ square, $4.5 \mathrm{cycle} / \mathrm{deg}$ distractors at $10^{\circ}$ eccentricity. The rasters are aligned on saccade initiation and are sorted according to saccade latency. The time of target presentation is indicated by the solid circle in each raster line. The ordinate represents $200 \mathrm{~Hz} . B$, Discharge rate in the $100 \mathrm{msec}$ before saccade initiation plotted as a function of target direction for detection and search trials. The parameters for the gaussian best-fit to the activity preceding the saccade to the target alone were $B=2 \mathrm{~Hz}, R=45 \mathrm{~Hz}, \Phi=165^{\circ}$, and $T_{\phi}=26^{\circ}$. The parameters for the difference-of-gaussian best fit to the activity. $100 \mathrm{msec}$ before saccades to the target presented with distractors were $B=27 \mathrm{~Hz}, R_{+}=62 \mathrm{~Hz}, \Phi_{+}=172^{\circ}, T_{+}=29^{\circ}, R_{-}=26$ $\mathrm{Hz}, \Phi_{-}=163^{\circ}$, and $T_{-}=158^{\circ}$.

curves. For $21 \%$ of the tonic visual neurons the difference-ofgaussian function accounted for more of the variance even allowing for the greater degrees of freedom; thus, these cells met this criterion for the existence of suppression flanking the re- ceptive field. For $17 \%$ more of the FEF cells the premovement activation appeared to be more attenuated when the target was near as compared to far from the receptive field. But although a difference of gaussians could describe the variation of premovement activation as a function of target location, the MSC statistic was larger for the best-fit single gaussian. Accordingly, by this strict criterion these cells were defined as lacking suppressive surrounds.

The spatial parameters from the best-fit gaussian and difference-of-gaussian curves provide estimates of the spatial extent of FEF response fields and suppressive surrounds. The width of the response field was estimated by the tuning $\left(T_{\phi}\right)$ of the gaussian curve best-fit to the variation of activity when the target was presented alone. The value, which was calculated in polar angle, was converted to visual field angle according to the eccentricity of the stimuli using the law of cosines. Based on the gaussian curves fit to the activity before saccades to the target presented alone for all of the cells, the average $( \pm \mathrm{SEM})$ response field width was $12 \pm 0.8^{\circ}$ (maximum $=26^{\circ}$, minimum $=3^{\circ}$ ). The spatial extent of the suppressive zone was estimated in two ways. First, based on the tuning of the subtractive component of the difference-of-gaussian equation $\left(T_{-}\right)$, the mean value for the width in the visual field of the suppressive zones was $13 \pm 2.0^{\circ}$ (maximum $=27^{\circ}$, minimum $=4^{\circ}$ ). This average value was just $1^{\circ}$ larger than the width of the excitatory response field estimated from $T_{\phi}$, but when compared to the estimate of the excitatory field width derived from the additive component of the difference-of-gaussian $\left(T_{+}\right)$, which was $10 \pm 1.5^{\circ}$ (maximum $=18^{\circ}$, minimum $-3^{\circ}$ ), the suppressive surround was larger than the facilitatory zone by on average $5 \pm 1.8^{\circ}$ (maximum $=17^{\circ}$, minimum $=0.1^{\circ}$ ). The second estimate of the width of the suppressive zone was the separation of the minima of the best-fit difference-of-gaussian function; these values averaged $14 \pm 1.6^{\circ}$ (maximum $=20^{\circ}$, minimum $=7^{\circ}$ ). As mentioned, the suppression was commonly asymmetric about the receptive fields. The absolute value of the separation in the visual field between the center of the facilitatory component $\left(D_{+}\right)$and the center of the subtractive component $\left(D_{-}\right)$averaged $6+2.0^{\circ}$ (maximum $=23^{\circ}$, minimum $=0.4^{\circ}$ ). We could discern no relationship between the location of the response field and the distribution of the suppressive regions in the visual field; in particular, we did not find that suppression of the distractor-evoked response was systematically stronger or weaker when the target was in the same or opposite hemifield as the response field.

We estimated the strength of the suppression of the distractorelicited response by the target when it fell in the flanking regions. One measure was the average of the discharge rate when the target fell in the suppressive zone on either side of the response field divided by the discharge rate when the target was distant from the response field. The average of this suppression ratio was $0.69 \pm 0.05$ (maximum $=0.99$, minimum $=0.35$ ). Another estimate of the rclative strengths of the facilitatory and suppressive components was the ratio of the response magnitude coefficients $\left(R_{-} / R_{+}\right)$. For neurons best-fit by the difference-ofgaussian function, the average ratio was $0.85 \pm 0.11$ (maximum $=1.83$, minimum $=0.44$ ).

\section{Manipulation of saccade production}

Previous work has shown that the activation of many visually responsive cells in FEF is enhanced if the stimulus is used as the target for a saccade (Goldberg and Bushnell, 1981). We wanted to determine whether the evolution of activity we have 
observed in the tonic visual cells would occur if the search array was presented but the monkey was instructed not to make an eye movement. We did this using the nogo trial condition in which the central fixation spot changed color to signal the monkey that reward was contingent on maintaining fixation. In this condition on every trial in a set of blocks the nogo signal was given a constant $400 \mathrm{msec}$ before the stimuli were presented, and reward was contingent on maintaining fixation for $500 \mathrm{msec}$ after the detection or search stimuli were presented. We intended for this condition to minimize the monkeys' tendency to plan a saccade to the stimuli. To emphasize the fact that no movement was supposed to be made, we refer to the conspicuous stimulus in these trials as an oddball instead of a larget. If saccade production influences the activation of FEF visually responsive neurons, then we expected that the neurons would be less active in the nogo as compared to the go trial condition. Similarly, if saccade planning was necessary for the evolution of target selection in FEF neurons, we expected that the activation evoked by the search array in the nogo condition would not vary with the location of the salient oddball stimulus.

We compared the first $50 \mathrm{msec}$ of visually evoked activity following target presentation for 13 neurons during go and nogo detection trials and for 7 of these in go and nogo search trials. During detection trials 4 cells were significantly more active in go versus nogo trials (least significant median test with 81 trials, $\chi^{2}=5.19$, df $\left.=1, p=0.023\right)$, and 1 cell was significantly less active in go trials (median test with 103 trials, $\chi^{2}=14.1$, df $=$ $1, p=0.0002$ ). The criteria used in previous studies for enhancement or depression were ratios of responsiveness greater than 1.5 or less' than 0.67 (Goldberg and Bushnell, 1981). According to this criterion 4 neurons were enhanced and one showed the opposite effect when the target was presented alone. During search trials 4 of the 7 tested cells responded significantly better to the stimuli in go as compared to nogo trials (least significant median test with 244 trials, $\chi^{2}=9.47$, df $=1, p=$ $0.0021) ; 3$ cells had ratios of activation in go as compared to nogo trials greater than 1.5 . As a population, the visual responses in all go trials with the target presented either alone or with distractors were significantly greater than the responses in the corresponding nogo trials (median test with 937 trials, $\chi^{2}=41.4$, df $=1, p<0.0001)$.

We also examined the evolution of activation following presentation of the search stimulus array in nogo trials. Four of the 7 neurons tested in nogo search trials exhibited no difference in the pattern of activity throughrit the instructed fixation period according to whether the oddba. fell within or outside of the receptive field. However, 3 of the neurons did respond differently in nogo search trials when the oddball stimulus fell within or outside the receptive field. One FEF neuron that signaled oddball location during nogo search trials is shown in Figure 8. In go trials when the target was presented alone in the cell's receptive field, the neuron discharged briskly until the initiation of the saccade. When the target was presented alone in the hemifield opposite the response field, suppression of the ongoing activity occurred until the saccade. In nogo trials when the target was presented alone in the response field, the initial brisk activation decayed gradually. When the target was presented alone in the opposite hemifield while fixation was maintained in nogo trials, suppression was evident until the end of the trial. When the search display was presented in go trials, this cell discharged transiently followed by a period of reduced activity. The magnitude of the initial response did not vary with target direction
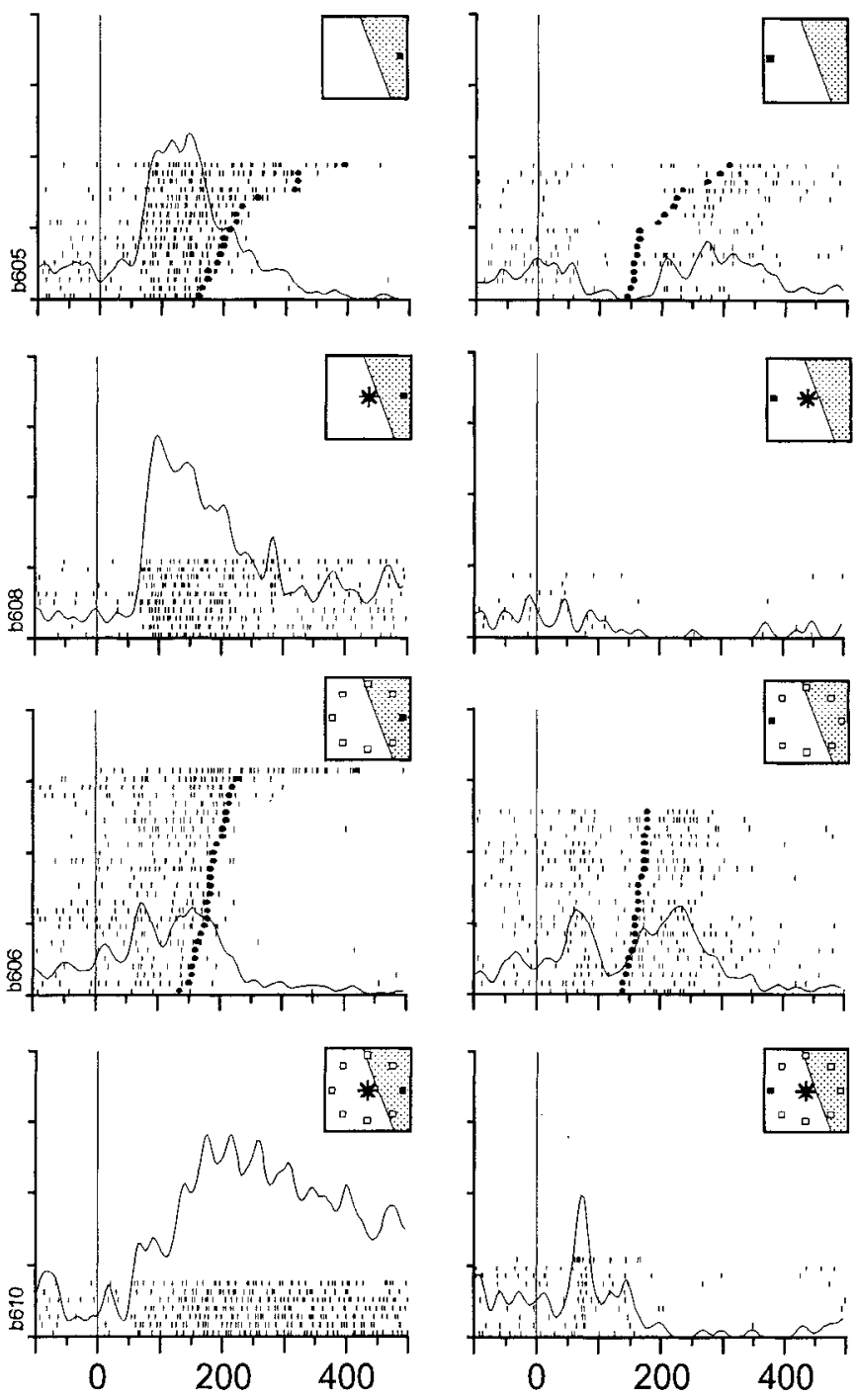

Time from Target (msec)

Figure 8. Activity of an FEF cell in detection and search conditions when the monkey was instructed to make or withhold the saccade. In the inset stimulus diagrams the absence of a fixation spot or presence of a central asterisk indicates whether a saccade was produced or withheld, respectively. The panels on the left illustrate the activity recorded when the target was at the most responsive position in the response field; the panels on the right illustrate the activity when the target was outside the response field. The target was a green square presented alone or with 7 red square distractors. The ordinate scale represents $200 \mathrm{~Hz}$.

(ANOVA $F=1.32$, df $=120$ ). If the target was outside the receptive field, the lack of activation persisted until the saccade was generated. On the other hand, if the target of the search display was in the receptive field, then this neuron discharged until the saccade to the target. When the search array was presented after the monkey received the nogo instruction, the level of the first $50 \mathrm{msec}$ of activation was not statistically different when the oddball stimulus was within or outside of the response field (ANOVA $F=0.96$, df $=48$ ). However, it is clear that beyond $100 \mathrm{msec}$ after stimulus presentation the pattern of activation was markedly different when the oddball stimulus was in the receptive field compared to when a distractor was in the receptive field. Even though no saccade was produced during the trial, if the oddball stimulus was in the response ficld, the cell discharged in a prolonged fashion until the reward was giv- 

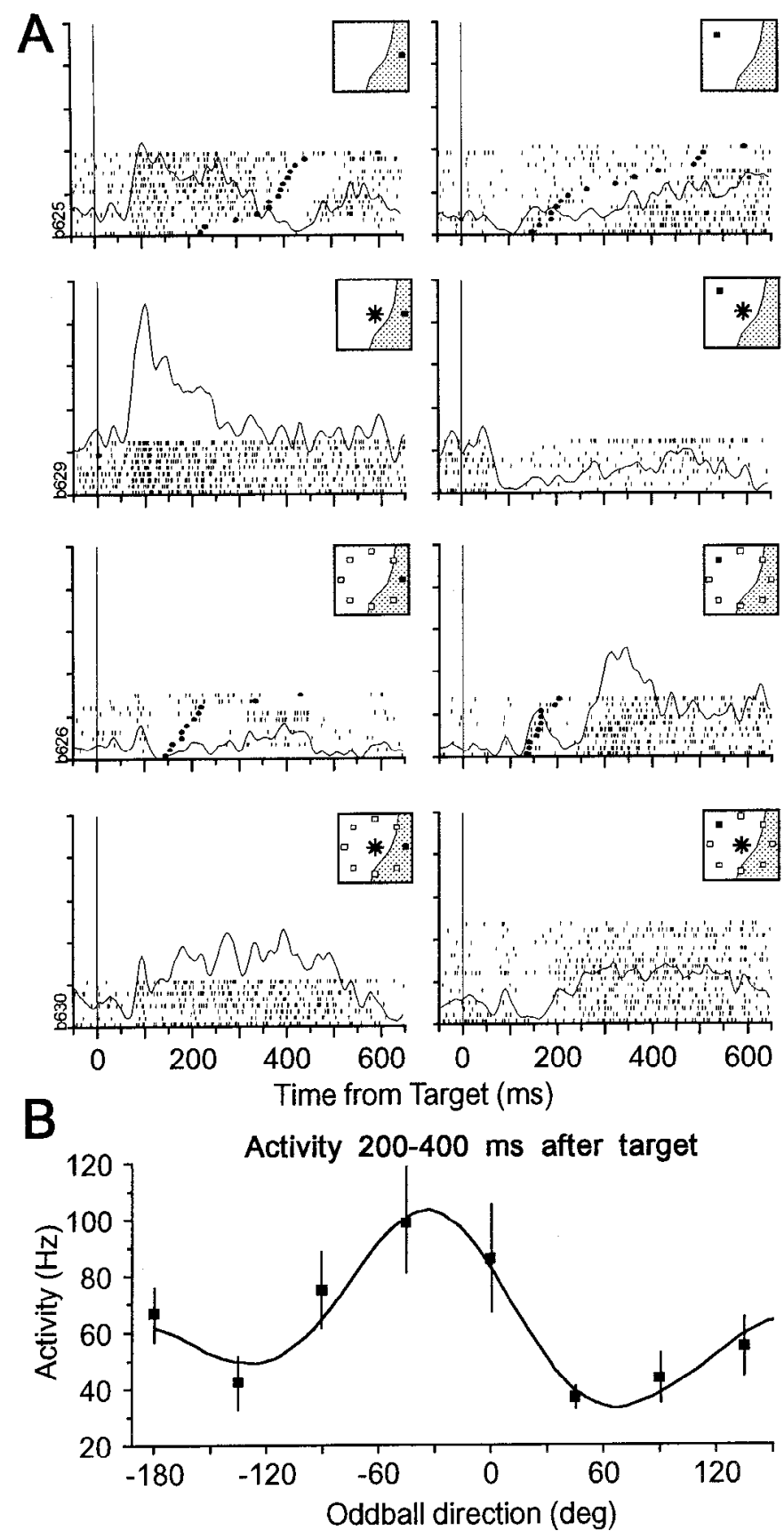

Figure 9. Activity of an FEF cell that was more active when a saccade was withheld. $A$, The target was a green square presented alone or with 7 red square distractors. The ordinate scale represents $250 \mathrm{~Hz}$. B, Variation of activity as a function of oddball direction measured from 200 to $400 \mathrm{msec}$ after search array presentation. Even during the nogo trials this cell exhibited suppressive response field flanks, the activity being better fit with a difference of gaussian function with the parameters $B$ $=80 \mathrm{~Hz}, R_{+}=126 \mathrm{~Hz}, \Phi_{+}=-30^{\circ}, T_{+}=49^{\circ}, R_{-}=104 \mathrm{~Hz}, \Phi_{-}=$ $-19^{\circ}$, and $T_{-}=87^{\circ}$.

en and the stimuli were removed from the screen. However, if the conspicuous stimulus was in the hemifield opposite the response field, then this neuron responded to the distractor in the response field with a brief burst followed by prolonged attenuation of activity below the baseline rate even though distractor stimuli were present continuously in the receptive field.

The cell shown in Figure 9 was significantly more active during nogo as compared to go detection trials (median test with
103 trials, $\chi^{2}=14.1, \mathrm{df}=1, p=0.0002$ ) and was also notable because the suppressive receptive field flanks were evident in the activation in both go and nogo search trials. This cell resembled others that were suppressed by stimuli appearing in the hemifield opposite the response field. Such suppression was especially evident when the target was presented alone outside the response field after the nogo instruction. When the target was presented with distractors in go search trials, the response to the search array was significantly less than that to the target presented alone (median test with 343 trials, $\chi^{2}=19.3$, df $=1, p$ $<0.0001$ ). The initial visual response to the search array in go trials did not vary significantly with target direction (ANOVA $F-1.07$, df -80 ). If the target of the search array was in the response field, after the initial weak response the neuron generated no more activity unless the saccade had a latency greater than $200 \mathrm{msec}$ in which case a low rate of activation appeared that lasted until the saccade was generated. Only a very weak response was seen if a distractor was in the response field and the saccade was directed away from it. In contrast, if the search array was presented after the nogo instruction, then the initial visual response of the cell was slightly but not significantly greater than that measured in trials when the saccade was generated (median test with 361 trials, $\chi^{2}=3.16$, df $=1, p=$ 0.076 ). The initial brief pulse of activity did not vary with oddball direction (ANOVA $F=1.57$, df $=103$ ). Subsequently, though, the pattern of activation was different when the oddball as opposed to a distractor was in the response field. When the oddball stimulus of the search array was in the response field but no saccade was made, this neuron continued to discharge until the reward was given on some but not all trials. When the oddball stimulus appeared in the hemifield opposite the response field, the brief initial response was followed by a $50 \mathrm{msec}$ period of attenuation followed by another period of prolonged activation. The level of activation during the period from 200 to 400 msec after the search display was presented varied in a systematic fashion according to where the oddball stimulus fell relative to the response field. Figure $9 B$ illustrates that the activity during this period varied in a center-surround fashion, being better fit by the difference-of-gaussian function (MSC $=0.433$ ) than the single gaussian (MSC $=0.363$ ), even though the monkey was rewarded for withholding a saccade during that period. During go search trials this neuron also exhibited the suppressive zone flanking the response field.

The differential activity observed in nogo search trials can be interpreted several ways. One possibility is that the activity reflects the establishment of a motor plan to make a saccade to the oddball once an eye movement is permitted. To determine whether the monkeys were planning a saccade to the oddball stimulus even though execution was prohibited during the trial, we analyzed the trajectory of the first saccade monkeys made after receiving the reward at the end of the trial. Following the nogo trials when the search display was presented, monkeys often showed a strong tendency to shift gaze to the conspicuous oddball stimulus even though no reward was given for this behavior. This tendency was pronounced during recording from the cells illustrated in Figures 8 and 9. However, during recording from another FEF ncuron that was significantly more active if the oddball was in the receptive field, the monkey did not tend to look at the oddball stimulus after each trial.

\section{Discussion}

This study provides new information about how the brain selects the targets for eye movements. Neurons in FEF reflect if not 
participate in the processing needed to identify the location of a salient stimulus among an array of distractors. The visual responses of FEF neurons were modulated by the presence of stimuli outside their receptive field, by the readiness to make a saccade as well as by whether the stimulus in the receptive field was the target. The movement related activity of FEF neurons represented the outcome of the decision process, being active in relation to the saccade produced regardless of the visual array.

\section{Visual response of FEF neurons}

Burman and Segraves (1994) investigated neural activity in FEF related to target selection in monkeys scanning natural images. On average, visually responsive cells were more active before saccades to features in their receptive field, and were suppressed before saccades to features outside the receptive field. This finding should not be considered inconsistent with our results. Whereas in Burman and Segraves' experiment the image was visible throughout the recording period, in our experiment the stimuli were flashed on after the monkeys fixated the central spot. The early nonspecific activation we observed probably represents a transient on-response.

The absence of a difference in the initial responses to the target and distractors distinguished by color and form indicates that FEF neurons are not stimulus specific. This conclusion, although consistent with previous physiological work in FEF (Mohler et al., 1973), has to be reconciled with the observation that FEF receives visual afferents from prestriate cortical areas in which neurons respond selectively to stimulus color, form, or motion direction (Schall et al., 1995). FEF visual responses are not feature selective perhaps because they receive convergence from cells with many different stimulus preferences.

The initial visual response of FEF cells to the search array was attenuated relative to the response to the target presented alone. If FEF visual cell responses reflected summation of the visual stimuli falling in the receptive field, then the activation evoked by the search array should have been greater than that evoked by the target alone because the receptive fields of most FEF ncurons were large cnough to encompass more than one element of the search array. The attenuated response to the search array may, therefore, be a consequence of spatial antagonism within or around FEF receptive fields. In fact, we observed suppression of FEF visual activity by stimuli presented alone in the hemifield opposite the receptive field. Such suppression has to our knowledge not been reported previously for FEF.

The response of many FEF visual neurons is enhanced if the stimulus is the target for a saccade (Wurtz and Mohler, 1976; Goldberg and Bushnell, 1981). This phenomenon could also account for the reduced initial response to the search array. When the search array appeared, it took time to process the image to ascertain whether the stimulus in the response field was the target or not. Using a nogo trial condition, we examined how saccade planning influenced the visual responses of FEF cells during detection and search trials. We found that the initial visual responses were influenced by both the presence of distractors and readiness to make a saccade.

Further work is needed to understand the sources of the different phases of activation of FEF cells. One possibility is that the evolution of the target selection signals results from intrinsic processing in FEF. Another possible origin of the multiphasic activation of FEF neurons is sequential activation by afferents with different specificities and timecourses. Visual afferents to
FEF arrive from a number of subcortical and cortical structures Thalamic input to FEF arrives from the pulvinar as well as intralaminar nuclei in which visual and saccade-related responses have been recorded (Schlag-Rey and Schlag, 1989; Petersen et al., 1987). The subcortical visual response latencies, ranging from 45-80 msec (Thompson and Schall, 1994), correspond to the latency of the initial visual response of our FEF neurons FEF also receives afferents from both ventral and dorsal prestri ate visual cortical areas (Schall et al., 1995). One major source of afferents is from dorsal areas MT, MST, and LIP in which neurons have relatively short visual response latencies (40-80 msec) and are not selective for color or spatial frequency. Thus, the initial indiscriminate visual response of FEF cells we observed could arise from these dorsal visual areas and from the subcortical pathway. FEF is also innervated by ventral visual areas V4, TEO, and caudal TE where neurons have longer visual response latencies of $80-120 \mathrm{msec}$ and are selective for color and form (e.g., Tanaka et al., 1991; Oram and Perrett, 1992). Neurons in these areas are modulated by attention to stimuli in their receptive fields (Moran and Desimone, 1985), but such an influence takes more than $100 \mathrm{msec}$ to arise (Chelazzi et al., 1993; Motter, 1994). Accordingly, the later phase of selective activation in FEF that signals target location may arrive from the ventral visual areas that discriminate the target from the distractor.

\section{Eye movement-related activity}

The transformation from visual responses to motor commands may be mediated by tonic visual cells, which we have referred to as visuomovement cells in other work (Schall, 1991a,b; Schall and Hanes, 1993). These neurons exhibited a transition from an early, nonselective response to activation signalling whether the target was in the response field. We are now analyzing the timecourse of this decision process; preliminary results indicates that on average FEF tonic visual neurons begin to discriminate the target from a distractor around $140 \mathrm{msec}$ after presentation of the search array (Thompson et al., 1995). Some neurons exhibited a discrete, later selective phase of activation that was synchronized with target presentation (Figs. 4, 5). This unexpected discovery seems to be physiological evidence for a dissociation between stages of perceptual processing related to target localization and stages of postperceptual processing related to response generation.

The level of activation of visuomovement cells immediately before saccades to the target in the response field during visual search was the same as that before saccades to the target presented alone. However, when a distractor was in the response field of a visuomovement cell, the pattern of activation before saccades directed out of the response field varied in two major ways. Most commonly, the activation of visuomovement cells evoked by distractors in the response field decayed or was suppressed even though the stimuli were still present. However, even before saccades directed opposite the response field the activity clicited by the distractor in the response field was not completely suppressed. This residual neural activity could result in occasional misdirected saccades. In several visuomovement neurons the distractor-evoked activity was more attenuated if the target was near the movement field. We saw no evidence that the pattern of local suppression bore any simple relationship to the location of stimuli in the visual field. The variation of presaccadic discharge as a function of search target direction that we observed can be described as a central excitatory zone 
flanked by suppressive regions, a pattern resembling that observed in other cortical areas and subcortical structures (Kuffler, 1953; Rodieck, 1965; Enroth-Cugell and Robson, 1966; Allman et al., 1985; Saito et al., 1986; Desimone and Schein, 1987; Hawken and Parker, 1987; Knierim and Van Essen, 1992; Olavarria et al., 1992). Thus, a basic mechanism of sensory coding may subserve the guidance of eye movements in complex images. The flanking suppression may reduce the probability of producing an errant saccade to a distractor in the response field when the target is nearby.

To investigate the linkage between the evolution of activity related to target selection in FEF and the production of saccades, we collected data using nogo trials. We discovered ncurons that responded more when the oddball stimulus of the search array was in the response field even when fixation was maintained for at least $500 \mathrm{msec}$. This neural modulation may be related to late enhancement (Goldberg and Wurtz, 1972) due to covert planning of a saccade to the salient stimulus. In fact, while these data were collected, the monkey did tend to make an unrewarded gaze shift to the oddball stimulus after the trial.

Finally, Burman and Segraves (1994) and we in this and earlier work (Hanes et al., 1995) found that the activity of movement cells in FEF reflected the metrics but not the visual context in which saccades were produced. A lack of differential activation preceding saccades produced in different visual environments indicates that the movement cell population lies at the distal end of the target decision process. This conclusion is consistent with the anatomical organization of FEF movement neurons which innervate the intermediate layers of the superior colliculus (Segraves and Goldberg, 1987) in which neurons reflect the outcome of the saccade target selection process (Ottes et al., 1987; Glimcher and Sparks, 1992).

\section{References}

Akaike $H$ (1973) Information theory and an extension of the maximum likelihood principle. In: 2nd International symposium of information theory (Petrov BN, Csazi F, eds). Budapest: Akademiai Kiado.

Akaike $H$ (1976) An information criterion. Math Sci 1:5-9.

Allman JM, Miezin F, McGuinness E (1985) Stimulus specific responses from beyond the classical receptive field: neurophysiological mechanisms for local-global comparisons of visual motion. Annu Rev Neurosci 3:532-548.

Bruce CJ, Goldberg ME (1985) Primate frontal eye fields. I. Single neurons discharging before saccades. J Neurophysiol 53:603-635.

Burman DD, Segraves MA (1994) Primate frontal eye field activity during natural scanning eye movements. J Neurophysiol 71:12661271

Chelazzi L, Miller EK, Duncan J, Desimone R (1993) A neural basis for visual search in inferior temporal cortex. Nature 363:345-347.

Colby CL, Duhamel J-R (1991) Heterogeneity of extrastriate visual areas and multiple parietal areas in the macaque monkey. Neuropsychologia 29:517-537.

Desimone R, Schein SJ (1987) Visual properties of neurons in area V4 of the macaque: sensitivity to stimulus form. J Neurophysiol 57:835868.

Dow BM, Snyder AZ, Vautin RG, Bauer R (1981) Magnification factor and receptive field size in foveal striate cortex of the monkey. Exp Brain Res 44:213-228.

Enroth-Cugell C, Robson JG (1966) The contrast sensitivity of retinal ganglion cells of the cat. J Physiol (Lond) 187:517-552.

Felleman DJ, Van Essen DC (1991) Distributed hierarchical processing in the primate cerebral cortex. Cereb Cortex 1:1-47.

Fries W (1984) Cortical projections to the superior colliculus in the macaque monkey: a retrograde study using horseradish peroxidase. $\mathrm{J}$ Comp Neurol 230:55-76.

Glimcher PW, Sparks DL (1992) Movement selection in advance of action in supcrior colliculus. Nature 355:542-545.

Goldberg ME, Bushnell MC (1981) Behavioral enhancement of visual responses in monkey cerebral cortex. II. Modulation in frontal eye fields specifically related to saccades. J Neurophysiol 46:773-787.

Goldberg ME, Wurtz RH (1972) Activity of superior colliculus in behaving monkey. II. Effect of attention on neuronal responses. J Neurophysiol 35:560-574.

Hanes DP, Thompson KG, Schall JD (1995) Relationship of presaccadic activity in frontal eye field and supplementary eye field to saccade initiation in macaque: Poisson spike train analysis. Exp Brain Res 103:85-96.

Hawken MJ, Parker AJ (1987) Spatial properties of neurons in the monkey striate cortex. Proc R Soc Lond [Biol] 231:251-288.

Hubel DH, Wiesel TN (1968) Receptive fields and functional architecture of monkey striate cortex. J Physiol (Lond) 195:215-243.

Hubel DH, Wiesel TN (1974) Uniformity of monkey striate cortex: a parallel relationship between field size, scatter and magnification factor. J Comp Neurol 158:295-305.

Huerta MF, Krubitzer LA, Kaas JH (1986) Frontal eye field as defined by intracortical microstimulation in squirrel monkeys, owl monkeys and macaque monkeys. I. Subcortical connections. J Comp Neurol 253:415-439.

Knierim JJ, Van Essen DC (1992) Neuronal responses to static texture patterns in area V1 of the alert macaque monkey. J Neurophysiol 67: 961-980.

Kubota K, lonoike M, Mikami A (1980) Neuronal activity in the monkey dorsolateral prefrontal cortex during a discrimination task with delay. Brain Res 183:29-42.

Kuffler SW (1953) Discharge patterns and functional organization of the mammalian retina. J Neurophysiol 16:37-68.

Merigan WH, Maunsell JHR (1993) How parallel are the primate visual pathways? Annu Rev Neurosci 16:369-402.

Mohler CW, Goldberg ME, Wurtz RH (1973) Visual receptive fields of frontal eye field neurons. Brain Res 61:385-389.

Moran J, Desimone R (1985) Selective attention gates visual processing in the extrastriate cortex. Science 229:782-784.

Motter BC (1994a) Neural correlates of attentive selection for color or luminance in extrastriate area V4. J Neurosci 14:2178-2189.

Motter BC (1994b) Neural correlates of feature selective memory and pop-out in extrastriate area V4. J Neurosci 14:2190-2199.

Olavarria JF, DeYoe EA, Knierim JJ, Fox JM, Van Essen DC (1992) Neural responses to visual texture patterns in middle temporal area of the macaque monkey. J Neurophysiol 68:164-181.

Oram MW, Perrett DI (1992) Time course of neural responses discriminating different views of the face and head. J Neurophysiol 68:7084.

Ottes FP, Van Gisbergen JAM, Eggermont JJ (1987) Collicular involvement in a saccadic colour discrimination task. Exp Brain Res 66: $465-478$.

Parthasarathy HB, Schall JD, Graybiel AM (1992) Distributed but convergent ordering of corticostriatal projections: analysis of the frontal eye field and the supplementary eye field in the macaque monkey. $\mathrm{J}$ Neurosci 12:1168-1488.

Pigarev IN, Rizzolatti G, Scandolara C (1979) Neurons responding to visual stimuli in the frontal lobe of macaque monkeys. Neurosci Lett 12:207-212.

Rodieck RW (1965) Quantitative analysis of cat retinal ganglion cell responses to visual stimuli. Vision Res 5:583-601.

Saito H, Yukie M, Tanaka K, Kikosaka K, Fukada Y, Iwai E (1986) Integration of direction signals of image motion in the superior temporal sulcus of the macaque monkey. I Neurosci 6:145-157.

Sakamoto Y, Ishigura M, Kitagawa G (1986) Akaike information criterion statistics. Dordrecht: Reidel.

Schall JD (1991a) Neuronal activity related to visually guided saccades in the frontal eye fields of rhesus monkeys: comparison with supplementary eye fields. J Neurophysiol 66:559-579.

Schall JD (1991b) Neuronal activity related to visually guided saccadic eye movements in the supplementary motor area of rhesus monkeys. J Neurophysiol 66:530-558.

Schall JD, Hanes DP (1993) Neural basis of saccade target selection in frontal eye field during visual search. Nature 366:467-469.

Schall ID, Morel A, King DJ, Bullier J (1995) Topography of visual cortical afferents to frontal eye field in macaque: functional convergence and segregation of processing streams. J Neurosci 15:44644487.

Schlag-Rey M, Schlag J (1989) The central thalamus. In: The neuro- 
biology of saccadic eye movements (Wurtz RH, Goldberg ME, eds). New York: Elsevier.

Schnyder H, Reisine H, Hepp K, Henn V (1985) Frontal eye field projection to the paramedian pontine reticular formation traced with wheat germ agglutinin in the monkey. Brain Res 329:151-160.

Segraves MA (1992) Activity of monkey frontal eye field neurons projecting to oculomotor regions of the pons. J Neurophysiol 68:19671985.

Segraves MA, Goldberg ME (1987) Functional properties of corticotectal neurons in the monkey's frontal eye fields. J Neurophysiol 58 : 1387-1419.

Segraves MA, Park K (1993) The relationship of monkey frontal eye field activity to saccade dynamics. J Neurophysiol 69:1880-1889.

Shook BL, Schlag-Rey M, Schlag J (1990) Primate supplementary eye field. I. Comparative aspects of mesencephalic and pontine connections. J Comp Neurol 301:618-642.

Shook BL, Schlag-Rey M, Schlag J (1991) Primate supplementary eye field. II. Comparative aspects of connections with the thalamus, corpus striatum and related forebrain nuclei. J Comp Neurol 307:562583.

Siegal S, Castellan NJ (1988) Nonparametric statistics for the behavioral sciences. New York: McGraw-Hill.

Sokal RR, Rohlf FJ (1981) Biometry. San Francisco: Freeman.

Stanton GB, Goldberg ME, Bruce CJ (1988a) Frontal eye field efferents in the macaque monkey. I. Subcortical pathways and topography of striatal and thalamic terminal fields. J Comp Neurol 271:473-492.

Stanton GB, Goldberg ME, Bruce CJ (1988b) Frontal eye field efferents in the macaque monkey. II. Topography of terminal fields in midbrain and pons. J Comp Neurol 271:493-506.

Suzuki H, Azuma M (1977) Prefrontal neuronal activity during gazing at a light spot in the monkey. Brain Res 126:497-508.

Suzuki H, Azuma M (1983) Topographic studies on visual neurons in the dorsolateral prefrontal cortex of the monkey. Exp Brain Res 53: $47-58$.

Tanaka K, Saito H-A, Fukada Y, Moriya M (1991) Coding visual images of objects in the inferotemporal cortex of the macaque monkey. J Neurophysiol 66:170-189.

Thompson KG, Hanes DP, Tu FF, Schall JD (1993) Evolution of saccade target selection signal in frontal eye field during visual search. Soc Neurosci Abstr 19:27.

Thompson KG, Hanes DP, Schall JD (1995) Time-course of target selection in macaque frontal eye field during visual search. Soc Neurosci Abstr 21:000.

Thompson KG, Schall JD (1994) Macaque oculomotor thalamus: Temporal characteristics of visual and saccade related activity. Soc Neurosci Abstr 20:145

Tootell RBH, Silverman MS, Switkes E, De Valois RL (1982) Deoxyglucose analysis of retinotopic organization in primate striate cortex. Science 218:902-904.

Treisman A (1988) Features and objects: the fourteenth Bartlett memorial lecture. Q J Exp Psychol 40A:201-237.

Van Essen DC, Newsome WT, Maunsell JHR (1984) The visual field representation is striate cortex of the macaque monkey: asymmetries, anisotropies and individual variability. Vision Res 24:429-448.

Viviani $P$ (1990) Eye movements in visual search: cognitive, perceptual and motor control aspects. In: Eye movements and their role in visual and cognitive processes (Kowler E, ed), pp 353-393. Amsterdam: Elsevier.

Wolfe JM, Cave KR (1990) Deploying visual attention: the guided search model. In: AI and the eye (Blake A, Troscianko T, eds), pp 79-103. New York: Wiley.

Wurtz RH, Mohler CW (1976) Enhancement of visual responses in monkey striate cortex and frontal eye fields. J Neurophysiol 39:766772.

Yarbus $\Lambda \mathrm{L}$ (1967) Eye movements and vision. New York: Plenum. 